\title{
A framework to embed Asset Management in production companies
}

\author{
Roda I., Marco M. \\ Department of Management, Economics and Industrial Engineering, Politecnico di Milano, \\ Milano, Italy (e-mail: irene.roda@ polimi.it; marco.macchi@ polimi.it)
}

\begin{abstract}
The aim of this paper is to investigate how to embed Asset Management in production companies. A framework is defined based on literature analysis and focus groups findings, in which the fundamentals to guide the integration of Asset Management are systematized. Two dimensions are identified - the asset life cycle and the hierarchical level of the asset-control activities - and four founding principles - life cycle, system, risk and asset-centric orientation as levers to integrate Asset Management within an industrial organization. An empirical investigation is then developed through multiple case-study involving eight production companies in Italy, with the purpose to map the elements of the framework against the real mechanisms in the industrial practices. This allows testing the relevance of the framework itself and demonstrating its potential as a support for companies to implement gap analysis on AM practices. Empirical evidence on current practices of AM in production companies is contextually unveiled.
\end{abstract}

Keywords

Asset Management, Production systems asset management, Life cycle engineering, Management systems

\section{INTRODUCTION}

Nowadays physical Asset Management (AM) is established and recognized as a holistic process involving different functions within an organization in the management of the assets along their entire lifecycle. In particular, AM is intended as a paradigm shift in focus with respect to maintenance management. The asset is brought at the center of the management process towards value creation and maintenance is one of several activities to be done along the lifecycle of the asset ${ }^{1,2}$.

In the industry, AM finds its roots in terms of application in most capital-intensive sectors such as the oil \& gas, energy and network utilities sectors due to the inherent criticality of the impact of the assets on the business. Nevertheless, current challenges and opportunities in the industrial world such as globalization, aging of assets, emerging of new technologies, etc., are more and more rising the attention of production companies towards AM, both in the manufacturing and process production sectors ${ }^{3,4}$. More and more, companies are aware of the need to break down their knowledge departmental silos and to take a more holistic approach for generating value from the management of their own assets (i.e. production systems). Nevertheless, AM is still scarcely adopted by production companies as a business process. Managers are finding difficulties in 
understanding how to implement AM in their own reality ${ }^{5}$ and some dimensions of AM decisions are based more on intuition and visions rather than structured and well-tooled analyses ${ }^{6}$. Nowadays, the consensus has been reached about AM as an essential process, contributing to an organization's objectives ${ }^{7}$ and the publication of the body of standards ISO5500X on AM in 2014 supported reaching such consensus and understanding AM concepts at general level. Nevertheless, the standards provide general guidelines adaptable to any kind of asset and organization, but still lack of clear indications on how to tailor AM in the specific context of production companies.

Looking at the scientific body of knowledge about AM and, in particular, about $\mathrm{AM}$ in the production sectors, this is still fragmented and the collaboration between organizations and academic researchers is still under way to extend it ${ }^{8,9}$. Tailoring the AM discipline to establish an AM business process that fits the needs of specific sectors is still an open challenge ${ }^{10}$.

For these reasons, the main objective of this paper is to propose a framework that can guide managers in production companies to embed AM in their company. This framework should remain in alignment with the business objectives and be integrated with the rest of the organization.

The research question is: "How to support production companies to embed AM in their organization?" The answer cannot depend solely on the indications given by the standards, independently of the target application sectors. Therefore, based on literature review and focus groups, the paper firstly aims to systematize the fundamentals to embed AM in production companies within a framework. Then, an empirical investigation is developed through a multiple case-study in order to map the elements of the framework against the actions undertaken in the actual practices, to explain and validate the framework itself and to demonstrate its potential as support for companies for implementing gap analysis. This also unveiled empirical evidence on current practices of $\mathrm{AM}$ in production companies.

Section 2 of the paper describes the methodology adopted for the research. Section 3 illustrates the framework built based on literature analysis and focus groups in order to synthesize the fundamentals for embedding AM in production companies. Section 4 is dedicated to present and discuss the findings of the cross-case analysis, as emerged from the multiple case study by mapping the real mechanisms through the framework's elements. Finally, section 5 is dedicated to the conclusions and discussion of scientific and industrial contributions.

\section{Methodology}

The methodology used in this research was designed based on the works on research methods in AM by El-Akruti \& Dwight and Kusumawardhani et al. ${ }^{11,12}$. In particular, the retroductive research strategy was selected in accordance to the research's objective (Figure 1).

Figure 1 The four types of reasoning in AM research (Kusumawardhani et al., 2017) 


\begin{tabular}{|c|c|c|c|c|}
\hline & Inductive & Deductive & Abductive & Retroductive \\
\hline Objective & $\begin{array}{l}\text { To establish } \\
\text { universal } \\
\text { generalizations } \\
\text { from observations }\end{array}$ & $\begin{array}{l}\text { To test theories, to } \\
\text { eliminate false ones } \\
\text { and corroborate the } \\
\text { survivor }\end{array}$ & $\begin{array}{l}\text { To describe and understand } \\
\text { a phenomenon in terms of } \\
\text { the actor's motives and } \\
\text { understanding }\end{array}$ & $\begin{array}{l}\text { To discover } \\
\text { underlying } \\
\text { mechanisms to } \\
\text { explain the observed } \\
\text { regularities }\end{array}$ \\
\hline \multirow[t]{2}{*}{ Start } & $\begin{array}{l}\text { Accumulate } \\
\text { observations or } \\
\text { data }\end{array}$ & $\begin{array}{l}\text { Identify a regularity } \\
\text { to be explained }\end{array}$ & \multirow[t]{2}{*}{$\begin{array}{l}\text { Discover everyday common } \\
\text { concepts, meaning and } \\
\text { motives }\end{array}$} & $\begin{array}{l}\text { Document and } \\
\text { describe a regularity }\end{array}$ \\
\hline & $\begin{array}{l}\text { Produce } \\
\text { generalizations } \\
\text { based on } \\
\text { empirical data }\end{array}$ & $\begin{array}{l}\text { Construct a theory } \\
\text { and deduce } \\
\text { consequences }\end{array}$ & & $\begin{array}{l}\text { Construct a } \\
\text { hypothetical model of } \\
\text { a structure or } \\
\text { mechanism }\end{array}$ \\
\hline Finish & $\begin{array}{l}\text { Use these "laws" } \\
\text { as patterns to } \\
\text { explain further } \\
\text { observations }\end{array}$ & $\begin{array}{l}\text { Test the } \\
\text { consequences by } \\
\text { matching them with } \\
\text { data }\end{array}$ & $\begin{array}{l}\text { Develop a theory and } \\
\text { test it successively }\end{array}$ & $\begin{array}{l}\text { Find the real } \\
\text { mechanism by } \\
\text { observations and/or } \\
\text { experiments }\end{array}$ \\
\hline Applications & $\begin{array}{l}\text { To discover } \\
\text { generalizations }\end{array}$ & To test theories & $\begin{array}{l}\text { To understand } \\
\text { people's actions }\end{array}$ & $\begin{array}{l}\text { To verify the causal } \\
\text { structure or } \\
\text { mechanism }\end{array}$ \\
\hline
\end{tabular}

Retroduction represents an attempt to overcome the pitfalls of purely inductive or deductive research processes ${ }^{13}$. Theory is considered as conceptualization and not as ordering framework; this allows consulting and redeveloping theory in a close relationship with empirical information. Basically, retroductive research strategy involves the building of hypothetical models as a way of uncovering the real structures and mechanisms which are assumed to produce empirical phenomena. The model, if it were to exist and act in the postulated way, would, therefore, account for the phenomena in question ${ }^{14}$. Literature analysis and focus groups allowed defining the model. The model provides the basis for the observation and collection of qualitative and quantitative data ${ }^{11}$. Testing the relevance of the postulated model can be done through case study methods. In fact, as stated in ${ }^{11,12}$, due to the multi-disciplinary nature of AM research, the non-experimental and quasi-experimental methods (like case study) are the most suitable. Case study allows exploring evidences and testing the relevance of the postulated framework and model according to the retroductive approach's objective ${ }^{11}$.

With respect to the research steps, the first conceptualization step was based on literature analysis combined with focus groups developed with industrial exponents. In accordance to the applied research approach, not only a state of art review in the international scientific literature was conducted, but also an investigation on the industrial current practices was done. The search for related publications was mainly conducted as a keyword search, using as main keywords: «Engineering Asset OR Physical Asset OR Asset» AND «Management OR Management System» AND «Production System OR Production Line OR Equipment OR Industrial System OR Industry OR Manufacturing». Both library services such as Scopus or Google Scholar and a wider surfing in the web were addressed. Moreover, different focus groups were organized in order to collect insights from industry. In particular, one focus group was organized in the context of TeSeM Observatory (www.tesem.net) and around thirty companies representatives, mainly operations managers and maintenance managers, from different sectors (among which the mechanical, the food \& beverage, the chemical and the oil \& gas sectors) participated in a round table session. Focus groups at different companies premises were also organized involving a smaller audience to openly discuss about AM and its 
challenges and meanings. In particular, three smaller focus groups were organized involving AM responsibles of three companies from the chemical, food \& beverage and mechanical sectors. Each focus group lasted 3 hours in average and opinions were collected about the findings from the literature analysis. The result of this research phase is a framework for AM integration in production companies.

Secondly, an exploratory phase was implemented. In fact, based on the framework, the case study method was used in order to find the real mechanisms and verify the framework validity by observation. The study targeted eight production companies in Italy, selected among companies with a medium or high maturity level in Maintenance Management practices. In fact, it was assumed that only companies with certain level of maturity in Maintenance Management - one of the precursors of AM 15,16 - are ready enough to talk about and implement the wider concept of AM. The selection was possible thanks to the survey of the TeSeM observatory made with the purpose to benchmark the maturity in Maintenance Management practices, and counting on a sample of more than 300 companies up to 2015 (the maturity assessment of maintenance management practices adopts the method presented in (Macchi, Fumagalli, $2013)^{17}$ ). The selected companies belong to different industrial sectors in order to avoid biases and to cover a broader scope of the production industry. Table 1 shows the panel of companies selected for the case study.

Table 1. Case study: involved companies

\begin{tabular}{|c|c|c|c|c|}
\hline Case & Type & Sector & Core business* & People interviewed \\
\hline A & Large & Chemical & $\begin{array}{l}\text { Manufacture of basic chemicals, } \\
\text { fertilizers and nitrogen compounds, } \\
\text { plastics and synthetic rubber in } \\
\text { primary forms }\end{array}$ & $\begin{array}{l}\text { - Maintenance and } \\
\text { technical materials } \\
\text { Executive }\end{array}$ \\
\hline B & Large & Appliances & 2751 Manufacture of electric domestic & $\begin{array}{l}\text { - Site Industrial } \\
\text { Engineering } \\
\text { Manager }\end{array}$ \\
\hline $\mathrm{C}$ & Large & Steel & $2420 \begin{array}{l}\text { Manufacture of tubes, pipes, hollow } \\
\text { profiles and related fittings, of steel }\end{array}$ & $\begin{array}{l}\text { - Maintenance } \\
\text { Manager }\end{array}$ \\
\hline $\mathrm{D}$ & Large & Steel & 2400Manufacture of basic metals & $\begin{array}{l}\text { - Technical Director } \\
\text { - Maintenance } \\
\text { Manager }\end{array}$ \\
\hline $\mathrm{E}$ & Large & $\begin{array}{l}\text { Petrol- } \\
\text { chemical }\end{array}$ & $1920 \begin{array}{l}\text { Manufacture of refined petroleum } \\
\text { products }\end{array}$ & $\begin{array}{l}\text { - Maintenance } \\
\text { Manager }\end{array}$ \\
\hline $\mathrm{F}$ & Large & $\begin{array}{l}\text { Machine } \\
\text { tools }\end{array}$ & 2849Manufacture of other machine tools & $\begin{array}{l}\text { - Technical Functions } \\
\text { Manager }\end{array}$ \\
\hline
\end{tabular}




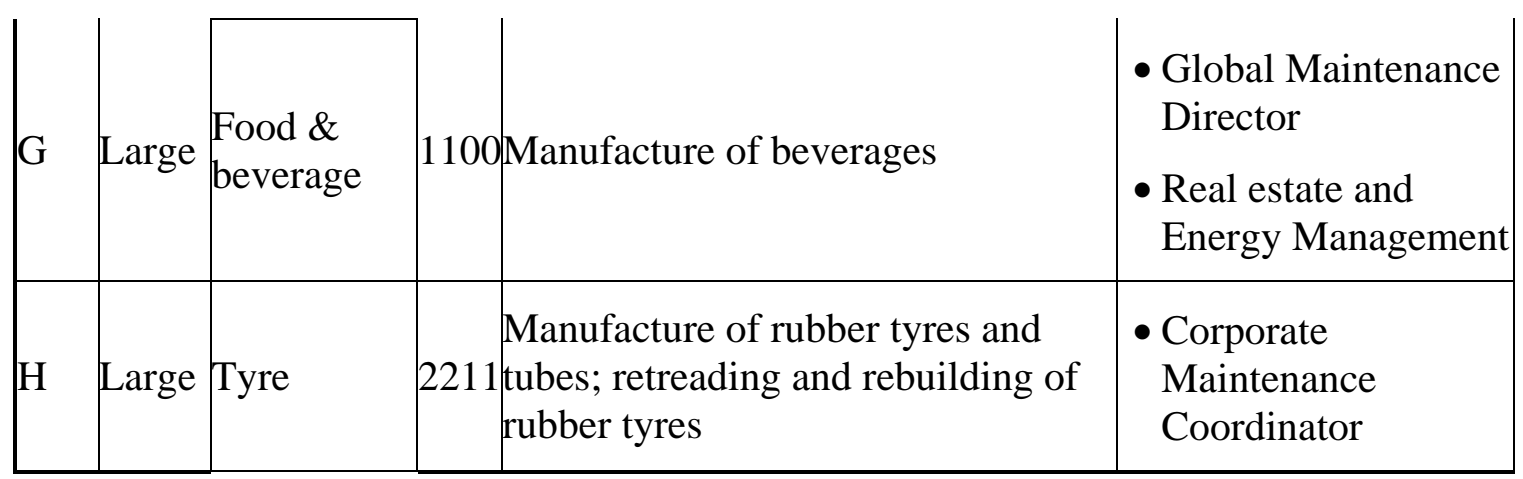

* Statistical Classification of Economic Activities in the European Community, Rev. 2 (2008)

The main source of the primary data for this research phase was a face-to-face semi-structured interview. Semi-structured interview brings the opportunity for the interviewee to share information relatively freely with the interviewer since such interviews possess some degree of flexibility in content ${ }^{18}$. Additionally, semi-structured interviews have the ability to light the road for the researcher by permitting practitioners to cooperate in the interview guidance to some extent, while still researcher as the interviewer keeps the control over the process (Berg, 2001). The nature of the interviews was chosen in order to allow starting the dialogue from the hypothesized framework and model in the previous research step. The face-to-face interview also allowed to observe not only the firm's environment, but also to notice any "weak signal" on the respondents' side - e.g. hesitation, irritation, non-verbal messages or non-given answers - that could provide a further dimension for the overall interpretation of the investigated phenomenon. The interviews were all recorded digitally and each of it lasted around 1 hour and a half in average. The interviews protocol was composed of eleven open questions. It was designed addressing the elements of the framework through different questions about the main issues that were identified through the literature analysis and focus groups in order to allow triangulation when analyzing the findings. The chosen unit of analysis was the company from the perspective of the maintenance, technical services or industrial engineering function. The data collected from the case studies were then analyzed using a uniform approach, interpreting the transcripts according to the coding technique, in order to denote the relevant concepts emergent during the interviews ${ }^{19}$. An overall of 75 firstorder codes were identified and the highest order themes reflected the elements of the framework. The analysis of the interviews and the main findings allowed confirming the elements within the defined framework and validating its application as a guide to integrate AM as well. In fact, the framework worked as a support for the companies involved in the case study to identify the AM level of integration in their organization and the existing gaps. Moreover, the case study implementation contextually allowed to unveil empirical evidence on current practices of AM in production companies.

\section{Framework definition}

\subsection{Literature analysis on existing frameworks}


As it is stated in Section 1 of this paper, the scientific body of knowledge about $\mathrm{AM}$ and, in particular about AM in the production sector, is still fragmented, and the collaboration between organizations and academic researchers is still under way to extend it ${ }^{8,9}$. A complete overview over the development process of the AM concepts and existing frameworks is provided in ${ }^{20}$. The authors show that, at general level, several AM frameworks have been defined so far in the literature. Nevertheless, the available frameworks that have been considered for AM are generally not comprehensive and do not consider a holistic approach, primarily focusing on just one stage of the lifecycle of an asset (commonly, the middle of life stage, addressing asset maintenance management) $20-22$

Some authors addressed the need to shift the focus from the technical aspects of physical assets to a more business-oriented AM approach. The recently published ISO 55000 standard goes in the same direction and defines guidelines that can be followed to develop an AM system. Nevertheless, the scientific \& technical literature about AM is either generic not addressing any specific sector (see for example the ISO5500X body itself) or dedicated to specific sectors such as the energy, building and constructed facilities, transportation infrastructures management or intangible assets management (human factor). In fact, $80 \%$ of papers found in the search engine Scopus, by looking at physical Asset Management as key word, are related to those sectors. Very few papers can be found dealing with AM in production companies. Nevertheless, several recent technical reports can be found about the topic ${ }^{5,23}$, showing the interest about AM in such industry.

Based on these findings, the aim of this research is to develop a literature analysis specifically focused on works illustrating AM as a consolidated discipline and, in particular, journal papers and books chapters proposing an AM framework addressing the production sector. The aim is to identify the main elements to define a framework to guide companies to embody AM in their realities.

The search for papers fitting the requirements of such analysis led to the identification of seven papers (Table 2). The findings of the cross-analysis of the papers is showed in the table. The main topics that are treated by each paper in describing the AM framework or scope have been identified under six main categories (Asset life cycle, Control levels, AM related organizational functions, Asset knowledge, Risk, System).

Table 2. Main aspects in the existing AM frameworks

\begin{tabular}{|c|c|c|c|c|c|c|c|}
\hline & & 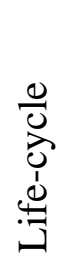 & $\begin{array}{l}\frac{n}{0} \\
\frac{0}{0} \\
\frac{1}{0} \\
0 \\
0 \\
0\end{array}$ & 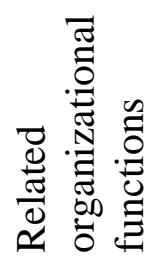 & 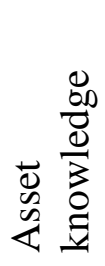 & $\frac{y}{a}$ & $\frac{E}{0}$ \\
\hline El-Akruti $a, b^{7,20}$ & 2013 & $\mathrm{x}$ & $\mathrm{x}$ & $\mathrm{X}$ & $\mathrm{X}$ & & \\
\hline
\end{tabular}




\begin{tabular}{|c|c|c|c|c|c|c|c|}
\hline Komonen ${ }^{6,24}$ & $\begin{array}{l}2006, \\
2014\end{array}$ & $\mathrm{x}$ & $\mathrm{x}$ & & & $\mathrm{x}$ & $\mathrm{X}$ \\
\hline $\begin{array}{l}\text { Amadi-Echendu, } \\
\text { Brown }{ }^{1}\end{array}$ & 2010 & $\mathrm{x}$ & $\mathrm{x}$ & $\mathrm{X}$ & & & \\
\hline Schuman, Brent ${ }^{21}$ & 2005 & $\mathrm{X}$ & & $\mathrm{X}$ & $\mathrm{x}$ & & \\
\hline Frolov $^{8}$ & 2010 & & & $\mathrm{x}$ & $\mathrm{x}$ & & \\
\hline Tam, Price 25 & 2008 & & $\mathrm{x}$ & & $\mathrm{x}$ & $\mathrm{x}$ & \\
\hline \multirow[t]{2}{*}{ Tranfield $^{4}$} & 2004 & $\mathrm{X}$ & $\mathrm{x}$ & & $\mathrm{x}$ & & \\
\hline & & 5 & 5 & 4 & 5 & 2 & 1 \\
\hline
\end{tabular}

The first two elements - asset life cycle and control levels - are the ones that are cited by most of the selected publications together with asset knowledge. Indeed, the first two aspects are considered as relevant to establish asset-related decision-making and they are not easily separated when analyzing AM, being intimately connected when a decision is taken ${ }^{20}$. The asset life cycle includes three relevant stages, Beginning of Life (BoL), Middle of Life (MoL), and End of Life (EoL) stages, wherein asset-related decisionmaking is required ${ }^{26}$. All selected papers highlight the importance of asset lifecycle management in their proposed frameworks except for ${ }^{25}$ that focus on the middle of life stage only and ${ }^{8}$ who don't stress the lifecycle aspect in their research.

Hierarchical levels of the asset-control activities (control levels) comprise the strategic, tactical, and operational levels wherein asset-related decisions are allocated, in terms of accountabilities, within the company organization. In their framework, ElAkruti, Dwight, and Zhang ${ }^{7}$ define a set of planning and control activities that exist at the three organizational levels, i.e. strategic, tactical or aggregate and operational. Komonen et al. ${ }^{6}$ highlight the three asset management levels in their framework for holistic management of production assets, and the three control levels can also be found in the works by Amadi-Echendu \& Brown, Tam \& Price, and Tranfield et al. ${ }^{1,4,25}$.

The other aspect that is cited by more than a half of the selected papers is the asset knowledge. The key issues pointed out by Tranfield et al. ${ }^{4}$ are the need to clarify the relationships between the asset a company owns ant the achievement of the company's strategic purpose, and which are the overriding purpose and function of the asset base. Moreover, according to the authors, companies need to have clear information about what asset they owns, what type, how many and their location. Knowledge of the assets can be gained through asset inspection and examination routines, condition assessment and monitoring ${ }^{4}$. Existing asset knowledge and asset performance evaluation are also two important elements in the work by Frolov et al. ${ }^{8}$. The relevance of asset conditions is also highlighted by Schumand and Brent ${ }^{21}$. According to them, the requirements with regard to system effectiveness in terms of reliability, availability and maintainability are of equal importance to the functional requirements of throughput, 
quality, capital cost, schedule, etc. In this same direction, El-Akruti et al. ${ }^{7}$ state that the value creation process expected by AM, can be detected in terms of the asset performance. In their paper, Tam and Price ${ }^{25}$ discuss about the relevance of an asset database that provides basic reference to information regarding assets' physical properties for strategic decisions at senior managerial level. According to the authors, the availability of useful data is paramount to making the best decision in asset management. Indeed, the role of information technology and systems is crucial to facilitate it ${ }^{4,25}$.

Other aspects that have been identified through the analysis of the paper are AM related organizational functions, risk and system. Regarding the first one, some papers advocate the importance of identifying and involving several organizational functions in the management of the assets. El-Akruti et al., identify functions involved in the asset life cycle activities and in supporting activities as well. The importance of a multidisciplinary approach is identified by Amadi-Echendu \& Brown, Frolov et al., Hastings, and Schuman \& Brent ${ }^{1,2,8,21}$ in order to enable an AM holistic approach, through the coordination among different kinds of actors. With this regard, clarifying accountability on assets is essential to ensure its sustainability in the company ${ }^{20,22}$.

The risk dimension is considered crucial in the framework by Tam and Price ${ }^{25}$ in which risk relates to potential hazardous events caused by failures. Risk analyses (both considering the risk related to the asset reliability and performance but also taking into account the business objectives, changes in the business environment, viewpoints of various joint-parties, the balanced governance of potential opportunities and versatile risks), is considered as an important input for the AM decision-making process, together with the technical and economic analyses, in the framework by Komonen et al. ${ }^{24}$.

Only the work by Komonen et al. ${ }^{24}$ among the selected publications, highlights the importance of the system perspective. In fact, the authors divide the AM framework they propose into three levels: corporate, plant and equipment level. Noticing that the plant and corporate levels have often been narrowly treated so far. According to the authors, different objectives and analysis should be performed at the different asset levels: "for example, the corporate executives should determine the role of each production unit. The plant-level management should model the production system, carry out criticality assessment [...]. At the production line, sub-process or equipment level, the important management processes would be, e.g., modeling of processes or technical functioning of equipment and taking care of criticality assessment". This aspect is not addressed in the other selected publications for this analysis.

\subsection{Focus groups findings}

Based on the focus groups organized with industrial exponents, the different elements identified through the literature analysis were discussed and their importance based on direct industrial opinions was collected.

First of all, it was evident that a full integration of asset life cycle and control levels is the heart of AM. On one hand, it was agreed that any time a decision is taken about assets, the whole life cycle should be considered analyzing what is inherited from 
the past in term of influencing variables, and how the future will be affected by the decision in case it is taken. On the other hand, it was apparent that a relevant factor for decision-making is the company organization; in particular, all three hierarchical levels of asset-control activities within the organization need to be involved, ensuring alignment through the implementation of feedback loops between the levels. Overall, the ability of a company to implement AM stands in the capability to integrate the two aspects into a robust and clearly defined AM system in its organization. This confirms what discussed in literature.

Moreover, the importance of adopting a long-term perspective in the management practice emerged from the focus groups. This means, on one side, to work on the integration among different functions that have to take decisions on the asset along the various stages of its lifecycle. On the other side, the need to have and use decisionmaking tools to support orientation towards a lifecycle perspective such as Life cycle cost or Total Cost of Ownership methodologies emerged in the discussions.

Among the other aspects identified, an important issue that was discussed is the need of deep and consolidated knowledge of the asset portfolio that must be managed by the company. Developing better knowledge about the asset base is considered as an urgent matter to build an AM system.

Interestingly, the stress of the industrial people involved in the focus groups was on the need to consider that industrial asset in the production sectors (both for process production and manufacturing) are typically very complex systems, composed by several machines and components connected among each other. For this reason the system aspect was stressed more than what is discussed in the literature. Indeed, as a result of the focus group, the need to adopt a hierarchical approach, considering different aggregation levels when managing assets (e.g. corporate, plant and equipment level), was evident, as fundamental element to take informed decisions.

Finally, the focus groups allowed to identify the risk dimension as a relevant aspect in the AM process. AM should allow managing assets but also the risk associated with the asset and with the decision-making processes on the assets. In particular, the focus is put on the operational risks related with uncertainty, i.e. the risk associated with the future asset behavior and its expected performance.

\subsection{Framework proposal}

Provided the findings of the literature analysis and of the focus groups, it was possible to define a framework (Figure 2) including the main elements required for AM embodiment in production companies.

In particular, the framework is composed by two dimensions and four founding principles. On one hand, the two dimensions are the asset control levels and the asset lifecycle. As it emerged from the literature analysis, these two aspects are relevant to establish asset-related decision-making and they are not easily separated, being intimately

connected when a decision is taken ${ }^{20}$. This is the reason why they are inserted in the 
framework as two dimensions: they represent the elements needed to position an assetrelated decision within the AM process. On the other hand, the four principles are: life cycle orientation; system orientation; risk orientation; asset-centric orientation. These are called principles since they define and guide the approach, methods, and systems to be adopted in order to integrate AM (and related decisions) within a company. As an example, in order to ensure that AM is integrated in a production company, the company has to be able to position any asset-related decision in terms of control level (strategic, tactical or operational), by simultaneously checking the alignment with the other levels, and in terms of asset lifecycle stages. Moreover, it has to approach the decision ensuring it is following the four principle. For example, let's consider, as decision, the investment in a new equipment within an existing plant. First of all, it is a strategic decision that must be aligned with the organizational strategy and guide activities and tactical and operational level. Then, it is a decision positioned in the MOL of the plant, as the plant is an existing one. Moreover, proper indicators and decision-making tools should be adopted to ensure lifecycle orientation (for example, considering the impact of the decision on total cost of ownership), system orientation (for example, considering the impact of the local decision on the performance of the whole pant), risk orientation (considering the operational risks connected with the investment decision) and assetcentric orientation (considering, as essential, the knowledge of the plant in which the new equipment will be installed and the kind of data that are required to be analyzed to guide the decision). More in detail, each founding principle is described hereafter.

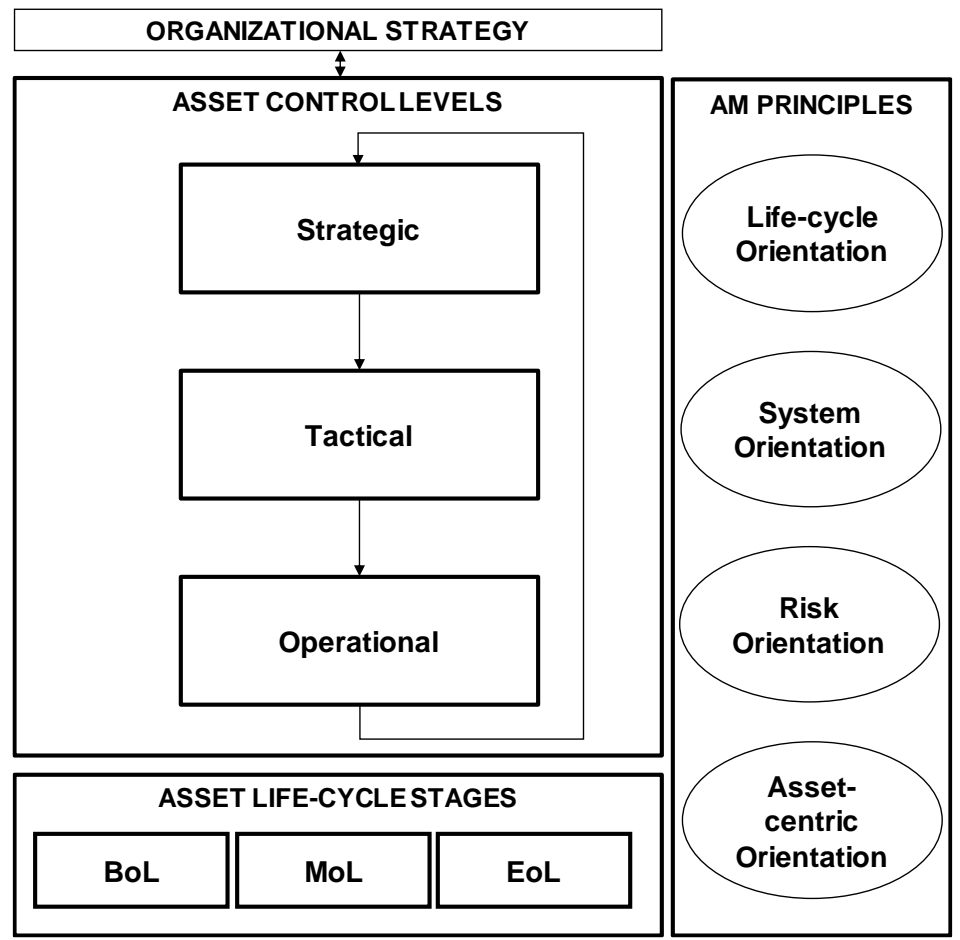

Figure 2. Framework for embedding AM in production companies

The adoption of life cycle orientation in decision-making means that the AM process should incorporate long-term objectives and performances to drive decisionmaking. Supporting tools can be adopted by the company to aid the achievement of this 
objective, such as the LCC (life cycle cost) / TCO (total cost of ownership) ${ }^{27,28}$. Moreover, given that the three stages of the life cycle of the assets - BOL, MOL, EOL differ in the scope of decisions, different organizational functions need to collaborate in the AM process, covering all organization's hierarchical levels ${ }^{20}$.

System orientation is another essential principle to ensure focusing efforts and resources on the right decisions. In particular, criticality of the assets at system level is fundamental for decision-making: as it is expressed in the ISO 5500X, "an asset is defined critical if it has potential to significantly impact on the achievement of the organization's objectives". As industrial assets are complex systems composed by various components interrelating among themselves, and such interactions, together with the state of each component, affect the state and performance of the system itself, the criticality of the assets at system level and the systemic effect of any local decision have to be considered to have a robust AM business process. Furthermore, the need to realize value from the asset systems motivate the relevance of a holistic consideration of asset systems in their entirety, and not merely of the individual components ${ }^{29}$.

Risk orientation should be also applied in decision-making. This should generally rely on the definition of risk given in ISO 31000:2009. Amongst the different types of risk, considering the operational risk in the industrial assets is then essential: the failure of critical assets proved to be the risk that is recognized by companies to have the biggest impact on business (according to the results of the industrial survey on operational risk management ${ }^{30}$ ). Being aware of such importance, leading companies use analytical tools to gain better visibility into the risks within their operations. Moreover, they establish a risk culture and empower the workforce with the information to be "predictive decisionmakers" ${ }^{30}$. Eventually, a risk orientation inevitably leads to the realization of value from assets: risk enables to take into account the likelihood and consequence of not fulfilling stakeholders' expectations, which is relevant to preserve the target values generated by the assets ${ }^{21,31}$.

Asset-centric orientation is another essential principle as the management of assets is dependent on knowledge about the organization's assets, in terms of both current equipment, business role of the assets and future prospects. In other words, asset managers need to have a practical working knowledge of the major assets so to be able to make sound business decisions ${ }^{2}$. Thus, it is advocated that it is necessary for AM implementation to have an asset common database where all the data about each asset and its components are stored together ${ }^{32,33}$. The asset database would provide basic reference to information regarding assets' properties, usable for strategic, tactical and operational decisions. Besides, tracking of changes during the life cycle of the asset is facilitated by a common database: it is an essential information for integrating the assetlife cycle dimension; it allows knowledge sharing about the assets along the different life cycle stages.

\subsection{Concluding remarks}

Overall the defined framework brings the four principles, as well as the two dimensions (asset control levels and life-cycle stages) together, considering them the 
elements that have to be considered by a company aiming to integrate AM in its organization. In fact, the two dimensions allow giving a frame in which to position assetrelated decisions by keeping a holistic perspective and providing a shared basis to the different functions and actors participating to the AM decision-making process. Those dimensions are also highlighted in the ISO5500X body of standards as fundamental for an AM system. Moreover, the four principles, guide companies to adopt the proper systems, tools, methods to ensure implementing an integrated AM process when taking asset-related decisions.

\section{Cross case study findings analysis}

The fundamentals defined in the framework were used as the basis for studying the actual level of integration of AM business process in the management systems of production companies and to subsequently understand the main gaps. The findings coming from multiple case study development are herein synthesized, focusing on each founding principle and the orientation towards it of each analyzed company.

\subsection{Life cycle orientation}

Based on the framework, life cycle orientation means: i) promoting an integrated organizational structure in which all the necessary competencies and organizational functions are involved at each stage of the life cycle of the asset; ii) adoption of long-term performance objectives and indicators in managing assets.

As far as the first issue regards, the findings from the case study analysis allowed assessing if companies present a proper level of integration among functions to manage the assets. In particular, by keeping the point of view of the maintenance function, a general trend towards integration emerged from the analysis. Nevertheless, there are still gaps at the organizational level to achieve a complete integrated system for the management of the assets.

At the early stage of the life cycle of the assets (BOL), dealing with design, construction, and commissioning, the desired condition is to get to closer cooperation among the various organizational functions such as design, purchasing, and maintenance. A certain trend towards this direction was detected in all the analyzed companies; however, the integration cannot be considered complete. What clearly emerged from the majority of the cases is the desire of the maintenance function to have a more active role in the BOL stage. As for the intermediate stage of the life cycle of the assets (MOL), dealing with use and maintenance, awareness of the role of maintenance as an "evolved" fundamental function that must work in an integrated manner with the various functions, and in particular with the production function, emerged. Nevertheless, in some cases, a certain "suffering" by the maintenance function is still perceptible that would like to participate more to decision-making, and that instead is often confined to managing assets in terms of reliability and availability in a still partially isolated way. Looking at the end of life stage of the assets life cycle (EOL) - dealing with renewal, disposal, recycling, reuse, as well as with potential life cycle extensions by, e.g., retrofitting or revamping (which means deciding to move the end of life ahead in time) -, it is the stage 
in which there is the lowest level of integration among the functions. In particular, the maintenance function in most of the analyzed companies mainly takes executive role, without participating in the decision-making process. It leaves wide rooms to achieve better integration.

As for the second issue of implementation of AM guided by long-term objectives and performances, interesting findings have emerged evaluating the tools and indicators used by companies to support decision-making. Concentrating on the investments planning and, in particular, the investments assessment, traditional methods are mainly adopted like ROI (Return on Investment), NPV (net present value) and IRR (Internal Rate of Return). Although these indicators theoretically imply the adoption of a longterm perspective, in practice, in the majority of cases, their calculation method consists of an accurate assessment of only CAPEX (the costs recognized in the capital of the company, i.e. Capital Expenditures) and of only including a rough estimate of OPEX (the operating costs for the year, i.e. Operational Expenditures). In particular, it is evident that the approximate estimate of OPEX is likely to underestimate the impact of the investment decision to the future performance of the asset that can generate inefficiencies and, therefore, hidden costs due to the inefficiencies.

Few are the cases where the investments assessment (made with the above methods) are flanked by other methods. Among them, it is worth citing: i) the use of a TCO model oriented to model the OPEX based on an accurate engineering estimate of the performance of the asset system, ii) the assessment of the satisfaction of the stakeholders, and/or iii) a RAM analysis (Reliability, Availability, Maintainability) for a provisional estimate of industrial plant performance losses (as failures are considered as relevant events leading to inefficiencies).

Overall, investments still seem a decision majorly featuring a financial problem, while all the companies recognize the need to increase the contribution of an engineering viewpoint to be integrated with the financial analysis. This would enable to evaluate the convenience of choices enriching the financial indicators with models capable of synthesizing the technical and operating characteristics of the industrial assets, with the ultimate goal to obtain adequate performance estimations, which are at the basis of informed financial analyses and robust decisions in the long-term.

\subsection{System orientation}

Regarding the system orientation, the case studies allowed investigating whether the complexity characterizing the industrial assets is taken into account in the decisionmaking processes, or not. In fact, industrial assets are typically systems composed of multiple components with their own RAM characteristics; and those components interact with each other to perform the requested function of the industrial asset.

All analyzed cases showed an awareness of the importance of adopting a system performances analysis, with the ultimate goal to take into account the effect that every local decision - hence, also the RAM characteristics of individual assets - inevitably has got at global level. This means, for example, making decisions for improvement of productivity in an industrial plant on the basis of a careful analysis of the criticality of the 
individual equipment with respect to the function they have for the production flow at system level.

Although awareness was shown by companies, today analyses keeping the systemic perspective are not implemented in a systematic way. This may be justified by various contingent reasons. In some cases, that is the case of a production line with no (or of limited capacity of) inter-operational buffers among the equipment, the asset (as a system) requires the operation of all the equipment (components) for its operation. In this specific case, each equipment assumes the same criticality at local and systemic levels, namely the OEE (Overall Equipment Effectiveness), measure centered at equipment level, would be sufficient to have an accurate approximation of the effect of local problems on systemic performances. In other cases, there is not yet a full integration of engineering techniques or tools, within the reliability and maintenance engineering systems, so to enable that the global effect of local decisions is fully analyzed; in fact, some companies are still relying on traditional KPIs like OEE keeping the local perspective: it is clearly not enough, when the complex interdependencies of individual assets affect the achievement of the performance of the system of assets (e.g. production capacity of the system). Finally, in one case, the systemic analysis is restricted to a limited number of decisions in the life cycle of the asset, and the use of some specialized engineering techniques but with no systematic approach throughout the life.

Overall, system orientation generally requires an enriched application of techniques through the extensive use of advanced engineering tools capable of systemlevel performances analysis, with particular concern to system effectiveness in terms of reliability, availability and maintainability as well as other functional requirements of throughput, quality, etc.

\subsection{Risk orientation}

As far as risk orientation regards, when making decisions related to assets, every company applies all the needed measures required in the legislative framework of the specific sector to reach the level of compliance for the management of critical risks related to safety and environmental impact. A differentiation then emerges in regard to how those operational risks - such as the risks linked to the effect of future behavior of assets on the expected technical performance - are managed. In this regard, the sectorial contingency has an impact on the practices adopted by the companies. In some sectors, the most capital-intensive ones, ensuring asset integrity is a priority due to its high impact on business. It is the case of the most advanced companies in terms of the systematic integration of typical approaches of RAM analysis and methods for operational risk management in AM. In general, the attention to the risks over performance and operation of the assets has been growing as a critical element in all analyzed cases. Concerning the uncertainty related to a risk, the aspect that stimulates a greater reflection is if the expected technical performance of the asset, and any inefficiency expected from its operation, are quantified in terms of cost to support decision-making by companies. As emerging evidence, what in general is still missing is an alignment between the system's technical performance measures and the financial indicators, which are the ones that are taken into account in the company to make decisions. Nonetheless, companies believe 
that an engineering analysis should support the final choices, aiming at a reduction of operational risks related to the losses in production efficiency, which eventually ensures a more informed decision-making.

Overall, the risk of not fulfilling stakeholders' expectations in terms of production efficiency and, then, related costs of the losses is still not fully analyzed, even if its relevance for the target values generated by the assets is apparent in all the cases.

\subsection{Asset-centric orientation}

The adoption of an asset-centric management approach appeared to be influenced by the sectors of the companies. In the most capital intensive sectors, the role of the assets and their performance is definitely recognized as central to ensure the production and the achievement of business objectives. It follows the high emphasis on ensuring clear ownership of the assets and collecting data referring to each asset.

In all cases, the relevance of the definition of a clear ownership of assets to ensure control and commitment to AM is recognized by the companies. The various analyzed companies, while proving to have all shared this need, have made different organizational decisions. In some cases, a centralized ownership at the level of maintenance / technical direction / industrial engineering functions has been chosen; in a few cases, the ownership was instead given to an executive belonging to the top management board.

In terms of information systems, in order to support an asset-centric management approach, information systems are seen with a central role, and in particular the maintenance information systems appear to play a relevant role for the MOL. Even so, the maintenance information systems are still partially integrated with other enterprise information systems and the need to move towards the definition of a better system, in which different kinds of data (technical and economical) related to the assets are collected and analyzed in an integrated manner, is recognized. This is considered an enabling element for the effective implementation of AM.

Overall, the issues addressed by asset-centric orientation are two-fold. On one side, from an organizational point of view, companies addressed the need to set clear responsibilities and commitment for AM implementation. On the other side, the need for an integrated information system to support AM along the lifecycle of the asset emerged.

\subsection{Concluding remarks and discussion on existing gaps}

The analysis of the interviews and the main findings allowed confirming the elements within the defined framework and validating its application as a guide to integrate AM. In fact, the framework worked as a support for the companies involved in the case study to identify the AM level of integration in their organization and the existing gaps.

Based on the findings described in the sections above, it was possible to make an overall diagnosis. The following table visualizes the level of integration of each principle 
within each company. Information are qualitative and are presented to have an overview on the AM integration level in each of the companies analyzed. Moreover, the last column of the table provides an overall value for the level of integration of each principle.

The main findings are illustrated in the reminder and are shown in Figure 3 in a qualitative way.

- Life-cycle orientation is the principle that is most integrated by companies even if there are still some cases where it needs to be improved.

- The least integrated aspect is the system orientation, in fact just one company uses a model in order to consider the global effect of local decisions when approaching decision-making, and yet not systematically.

- The company that resulted with the highest level of AM integration given the orientation towards the four principles is company F. Company F presented some weaknesses regarding risk orientation since future uncertainty is considered through average values based on estimations or historical values and not through a what if approach (scenario analysis) nor through a probabilistic approach.

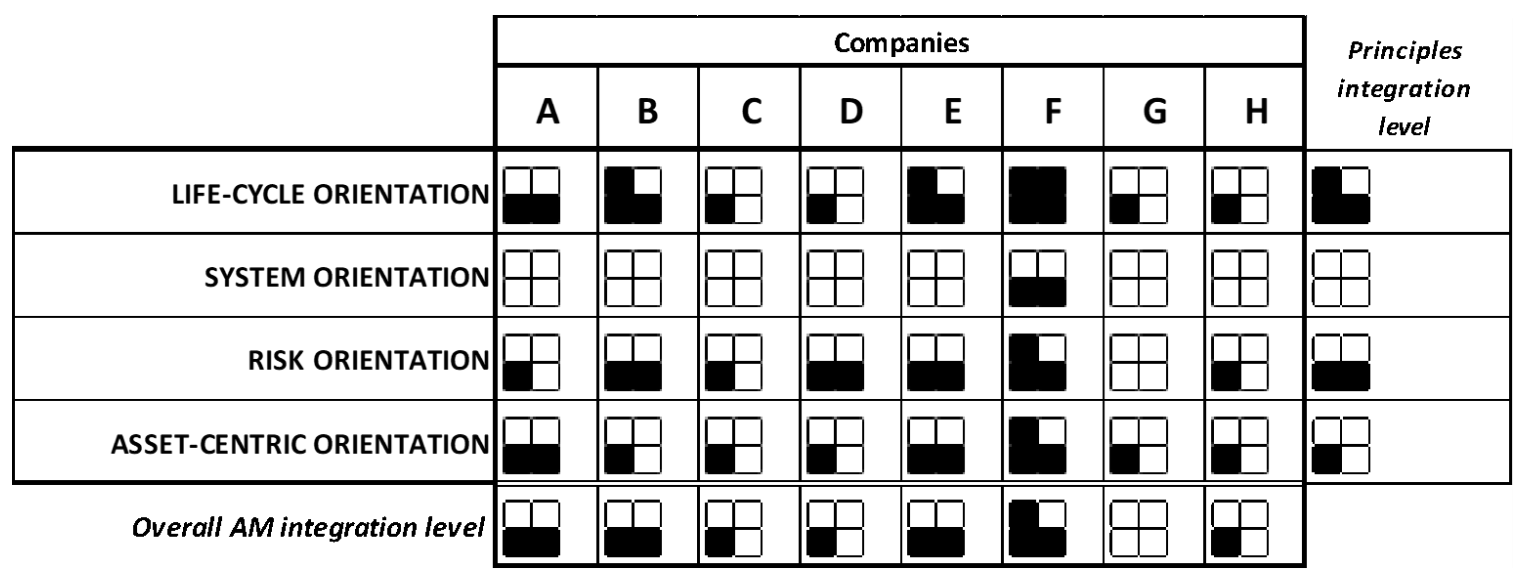

Figure 3. Cross case study findings

To conclude, it is worth remarking that the case studies were developed by considering companies belonging to different industrial sectors to have a general overview, and validating the framework as a guide for AM integration in production companies. The framework proved to be useful to assess the level of AM integration in a company, hence it can be used as a guide to identify activities to integrate AM in any production company. Even if the companies selected for the case study development are companies with high level of maturity in terms of Maintenance Management, when widening up the perspective over AM, gaps to be filled in have been identified. None of the companies resulted to fully incorporate the four founding principles for AM implementation. Lifecycle orientation is the principle that more companies are looking at in order to tend towards it (by means of re-organization, testing of new tools, etc.), while system orientation is still quite weak in all companies. Moreover, it is worth noticing that the gaps that have been identified regarding the level of integration of the AM in the companies not only are due to contingent reasons (industry, types of assets to manage 
etc.) but also to the low development level of the necessary technologies / methodologies. For example, the availability of a standard model for total cost of ownership, as a methodology to support the decision-making process, or the availability of performance indicators at system level, were pointed out in the majority of interviewed companies.

\section{Conclusions}

In this research, the AM integration process is addressed within the context of production companies.

From a scientific perspective, the contribution of this paper is the proposal of a framework for AM integration specifically thought and developed for production companies. The framework is derived from an analysis of existing frameworks in the literature, by integrating the main elements that were identified during the time by different authors and confirmed by industrial experts through the development of focus groups. The case study developed involving eight production companies allowed exploring evidences in industry and testing the relevance of the proposed framework.

From a practical point of view, the research findings are interesting for managers and engineers within this context (i.e. technical managers, operations managers and/or top managers), proposing a framework illustrating the principles to be considered in order to embed AM in their companies (Figure 2). Production sectors differ among each other and each single company is characterized by its own peculiarities. This is the reason why the framework is intended to provide the main principles to guide the AM integration in a company without indicating specific tasks to be implemented or tools to be used, making it useful for different companies.

Based on the lessons learnt from the case studies, we believe that companies have to get more and more aware of the importance of addressing AM by reflecting the four founding principles and by accordingly structuring an Asset Management system. Moreover, we would assert that the founding principles are actually a required background upon which the decision-making process can be developed, building both on the life cycle perspective and through alignment among the strategic, tactical and operational control levels within the organization. By adopting these measures, which are actually summarized in the AM framework presented in this paper, sustainable value creation from assets can be ensured.

\section{ACKNOWLEDGMENT}

The research work was performed within the scope of TeSeM Observatory (www.tesem.net). Moreover, the research work was performed within the context of SustainOwner ("Sustainable Design and Management of Industrial Assets through Total Value and Cost of Ownership"), a project sponsored by the EU Framework Programme Horizon 2020, MSCA-RISE-2014: Marie Skłodowska-Curie Research and Innovation Staff Exchange (RISE) (grant agreement number 645733). 


\section{REFERENCE}

1. Amadi-Echendu JE, Brown K. Definitions, Concepts and Scope of Engineering Asset Management. 2010. DOI: 10.1007/978-1-84996-178-3.

2. Hastings NAJ. Physical Asset Management. Springer Science \& Business Media (2009).

3. Korpi E, Ala-Risku T. Life cycle costing: a review of published case studies. Manag Audit J 2008; 23: 240-261.

4. Tranfield D, Denyer D, Burr M. A framework for the strategic management of longterm assets (SMoLTA). Manag Decis 2004; 42: 277-291.

5. Aberdeen Group. The asset management benchmark report: moving toward zero downtime [online]http://www.aberdeen.com (2006).

6. Komonen K, Kortelainen H, Räikkönen M. Corporate asset management for industrial companies: An integrated business-driven approach. In: Asset

Management: The State of the Art in Europe from a Life Cycle Perspective. 2014, pp. $47-63$.

7. El-Akruti K, Dwight R, Zhang T. The strategic role of Engineering Asset Management. Int J Prod Econ 2013; 146: 227-239.

8. Frolov V, Ma L, Sun Y, et al. Identifying Core Functions of Asset Management. In: Definitions, Concepts and Scope of Engineering Asset Management. 2010, pp. 1930 .

9. El-Akruti K. The strategic role of engineering asset management in capital intensive organisations. University of Wollongonghttp://ro.uow.edu.au/theses/ 3539 (2012).

10. Komonen K, Despujols A. Maintenance within physical asset management: A standardization project within CEN TC319. In: COMDEM. Helsinki, 2013.

11. El-Akruti K, Dwight R. Research methodologies for engineering asset management. In: ACSPRI Social Science Methodology Conference2010. Sydney, Australia

12. Kusumawardhani M, Gundersen S, Tore M. Mapping the research approach of asset management studies in the petroleum industry. J Qual Maint Eng; 23.

13. Sæther B. RETRODUCTION: AN ALTERNATIVE RESEARCH STRATEGY? 1998; 249: 245-249. 
14. Atkinson D. Approaches and Strategies of Social Research. Essay for Reasearch Methods Class ST700 2014; 700.

15. Al-Turki U. A framework for strategic planning in maintenance. J Qual Maint Eng 2011; 17: 150-162.

16. Liyanage JP, Kumar U. Towards a value-based view on operations and maintenance performance management. J Qual Maint Eng 2003; 9: 333-350.

17. Macchi M, Fumagalli L. A maintenance maturity assessment method for the manufacturing industry. J Qual Maint Eng 2013; 19: 295-315.

18. Bryman A. Integrating quantitative and qualitative research: how is it done? Epub ahead of print 2009. DOI: 10.1177/1468794106058877.

19. Corbin J, Strauss A. Basics of qualitative research: Techniques and procedures for developing grounded theory. Sage publications, 2014.

20. El-Akruti K, Dwight R. A framework for the engineering asset management system. J Qual Maint Eng 2013; 19: 398-412.

21. Schuman $\mathrm{C}$ a., Brent AC. Asset life cycle management: towards improving physical asset performance in the process industry. Int J Oper Prod Manag 2005; 25: 566579.

22. Amadi-Echendu JE. Managing physical assets is a paradigm shift from maintenance. In: Engineering Management Conference, 2004. Proceedings. 2004 IEEE International, pp. 1156-1160.

23. Eriksen L, Steenstrup K. Market Guide for Asset Performance Management, Gartner. 2017.

24. Komonen K, Kortelainen H, Räikkonen M. An asset management framework to improve longer term returns on investments in the capital intensive industries. In: London S (ed) Engineering Asset Management, pp. 418-432.

25. Tam ASB, Price JWH. A generic asset management framework for optimising maintenance investment decision. Prod Plan Control 2008; 19: 287-300.

26. Ouertani MZ, Parlikad AK, McFarlane DC. Towards an approach to Select an Asset Information Management Strategy. IJCSA 2008; 5: 25-44. 
27. El-Akruti K, Dwight R, Zhang T, et al. The role of life cycle cost in engineering asset management. In: Engineering Asset Management-Systems, Professional Practices and Certification. Springer International Publishing, pp. 173-188.

28. Roda I, Garetti M. TCO evaluation in physical asset management : benefits and limitations for industrial adoption. In: Grabot B et al. (ed) APMS 2014, Part III, IFIP AICT 440. 2014, pp. 216-223.

29. Xu Y, Elgh F, Erkoyuncu J. Cost Engineering for manufacturing: Current and future research. Int J Comput Integr Manuf 2013; 37-41.

30. Aberdeen Group. Operational Risk Management. Epub ahead of print 2007. DOI: $10.1057 / 9780230591486$.

31. Roda I, Parlikad AK, Macchi M, et al. A Framework for Implementing Value-Based Approach in Asset Management. Proc 10th World Congr Eng Asset Manag 2016; $487-495$.

32. Al-Najjar, Basim. Total quality maintenance: An approach for continuous reduction in costs of quality products. Journal of Quality in Maintenance Engineering 1996; 2: 4-20.

33. Kans M, Ingwald A. Common database for cost-effective improvement of maintenance performance. Int J Prod Econ 2008; 113: 734-747. 